\title{
Behavior of soybean oil-in-water emulsion stabilized by nonionic surfactant
}

\author{
Jyh-Ping Hsu* and Anca Nacu \\ Department of Chemical Engineering, National Taiwan University, Taipei, 10617 Taiwan, ROC
}

Received 16 April 2002; accepted 16 December 2002

\begin{abstract}
A soybean oil-in-water emulsion was prepared using nonionic Tween series surfactants. The effects of temperature, hydrophilic-lipophilic balance (HLB) value of the surfactant, and surfactant-to-oil ratio on the size of emulsion drops were investigated with an acoustic and electroacoustic devices. In the case of Tween 85, the influence of $\mathrm{pH}$ and electrolyte on the $\zeta$ potential of emulsion drops was examined. $\zeta$ potential appears to be strongly dependent on $\mathrm{pH}$, varying in the case of high concentrations of $\mathrm{NaCl}$ from +60 to $-90 \mathrm{mV}$. High concentrations of $\mathrm{Na}^{+}$and $\mathrm{K}^{+}$are capable of separating the oil phase from the emulsion. Divalent cations such as $\mathrm{Ca}^{2+}$ and $\mathrm{Mg}^{2+}$ lead to two points of zero charge at high concentrations, which is not observed for the case of hydrolyzable trivalent species like $\mathrm{Al}^{3+}$ and $\mathrm{Fe}^{3+}$. (c) 2003 Elsevier Science (USA). All rights reserved.
\end{abstract}

Keywords: Soybean oil emulsion; Nonionic surfactant; Electroacoustic measurement; $\zeta$ potential

\section{Introduction}

Use of vegetable oils such as palm, sunflower, and soybean oils began to diversify over the last years, spreading to nonfood areas. Since industrial firms are choosing to employ ingredients that are nontoxic, biodegradable, and not persistent in the environment and that come from renewable sources, soybean oil can now be found in lubricants, inks, paints, varnishes, and pesticide carriers. One possible way of using soybean oil is to incorporate it into an emulsion. The stability of an emulsion depends on several key parameters such as $\zeta$ potential and particle size. These parameters are greatly affected by the choice, concentration, and placement of the surfactant, on one hand, and by manufacturing technique and water/oil ratio, on the other hand.

Quite a few articles have discussed the effects of electrolyte and $\mathrm{pH}$ on the $\zeta$ potential of vegetable oils stabilized by a nonionic surfactant. Ho and Ahmad [1] and Ahmad et al. [2], for example, investigated the properties of several commercial palm oils in water emulsions stabilized by nonionic surfactant. In the case of palm olein emulsion stabilized by Emulgen 906, a nonionic, oil-soluble emulsifier, the effect of the presence of $\mathrm{Na}^{+}, \mathrm{Ca}^{2+}, \mathrm{Mg}^{+}, \mathrm{Zn}^{2+}$,

\footnotetext{
* Corresponding author.

E-mail address: jphsu@ccms.ntu.edu.tw (J.-P. Hsu).
}

$\mathrm{Cu}^{2+}, \mathrm{Al}^{3+}$, and $\mathrm{Fe}^{3+}$ on the $\zeta$ potential was studied. The $\zeta$ potential was found to be negative for all the $\mathrm{Na}^{+}, \mathrm{Ca}^{2+}$, and $\mathrm{Mg}^{2+}$ concentrations tested and for $\mathrm{pH}$ values higher 3 , and it reduced to zero for a $\mathrm{pH}$ lower 3 . For the rest of the cations the $\zeta$ potential was dependent on the adsorption of cationic hydrolyzed species on the surface of the emulsifier covering the oil particle. Negative $\zeta$ potentials were also reported for emulsion of aliphatic hydrocarbons [3]. Pipel and Ribbani [4] investigated liquid crystal formation in emulsion-stabilized mixtures of nonionic surfactants (Span and Tween). In a review about cosmetics, Fukushima [5] reported both negative and positive maxima in $\zeta$ potentials for emulsions using various oils, surfactants, and electrolytes. Recent works have investigated use of the acoustics and electroacoustics of emulsions and microemulsions [6-9]. Kong et al. $[7,8]$ described the effect of $\mathrm{KCl}, \mathrm{pH}$, temperature, and volume fraction on the electroacoustic behavior of sunflower oil in a water emulsion stabilized by SDS, or a mixture of SDS and different nonionic surfactants. The same technique was used to monitor the particle size distribution in a threecomponent system (heptane, water, and aerosol-OT), and the results were found to agree with those obtained using neutron scattering and small-angle X-ray scattering.

Several studies have dealt with soybean oil emulsions. Kako and Kondo [10] studied the stability of soybean oil emulsions containing a mixture of monoglyceride and di/tri- 
glyceride emulsifiers. The rheological properties of emulsifier films were investigated, and the influence of $\mathrm{pH}$ on the electrophoretic mobility of oil drops was discussed briefly. Miňana-Perez et al. [11] described the formation of soybean oil-in-water microemulsions using an extended surfactant. Soybean oil was employed in another study examining the effect of oil type on the phase behavior of oil-in-water microemulsions stabilized with nonionic surfactant. Long-chain trygliceride oils like soybean oil are more difficult to solubilize in aqueous solutions than single-chain oils. The effect of electrolyte was found to be detrimental for the microemulsion and could seriously alter the PIT leading to phase inversion [12].

In the present study we consider the electrokinetic properties of soybean oil-in-water emulsions stabilized with surfactants from the Tween series. The choice of emulsifier was dictated by the hydrophilic-lipophilic balance (HLB) values of the surfactants of this series, situated in the range 8-15, making them suitable for an oil-in-water emulsion. The surfactant dosage was much above the CMC in order to obtain almost complete coverage of the oil drop surface [7].

\section{Materials and methods}

Commercial cooking soybean oil (Uni-president, Taiwan) was used without further purification. The Tween series (Sigma) were used as surfactants. Lithium, sodium, potassium, calcium, magnesium, ferric, and aluminum chlorides of analytical grade were used. Since all of the samples investigated had been freshly prepared nothing was added to prevent microbial growth. The properties of the Tween series surfactants used including HLB values, molecular weight, and CMCs are summarized in Table 1 [13].

Except for the case when temperature effect was investigated, oil-in-water emulsions were prepared by mixing the emulsifier with oil and preheating to $70^{\circ} \mathrm{C}$. The mixture was introduced into an electrolyte solution, previously brought to the same temperature, and agitated with a magnetic stirrer. Further homogenization was performed with an ultrasonicator (Misonix) for $2 \mathrm{~min}$. Since this procedure raises the temperature caution was taken so that it did not exceed $70^{\circ} \mathrm{C}$. When the temperature effect was considered the procedure was repeated by keeping the temperature at a prespecified level. The samples were then stored at room temperature.

Several methods have been reported in the literature for estimation of the $\zeta$ potential of emulsion drops. Among these, microelectrophoresis appears to be most desirable [5] since all the other methods face the same problem that an emulsion needs to be diluted before measurement, which can cause modification in both emulsion drop size and surface charge. In our study both the $\zeta$ potential and the distribution of emulsion drop size were measured with DT-1200 acoustic and electroacoustic spectrometers (Dispersion Technology), which have the great advantage of recording the reading on an undiluted, concentrated emulsion sample. Acoustic spectroscopy is used to measure both the attenuation and the sound speed, and the electroacoustic spectroscopy is used to measure the colloid vibration current. The drop size distribution is calculated based on the ultrasound attenuation frequency spectra with frequency ranging from 1 to $100 \mathrm{MHz}$, and the $\zeta$ potential is obtained from the colloidal vibration current. Acoustic spectroscopy and electroacoustic spectroscopy are not totally independent of each other since

Table 1

Summary of the properties of the Tween series used [13]

\begin{tabular}{|c|c|c|c|c|c|c|}
\hline Surfactant & MW & HLB & $\begin{array}{l}\mathrm{CMC} \\
(\mathrm{mM})\end{array}$ & $\begin{array}{c}\text { Weight } \\
(\%, \text { w/w oil })\end{array}$ & $\mathrm{pH}$ & $\begin{array}{l}\zeta \text { potential } \\
(\mathrm{mV})\end{array}$ \\
\hline No surfactant & - & - & - & $\begin{array}{l}0 \\
0 \\
0 \\
0\end{array}$ & $\begin{array}{l}2.3 \\
4.3 \\
6.6 \\
8.1\end{array}$ & $\begin{array}{r}22.0 \\
4.2 \\
-22.1 \\
-24.3\end{array}$ \\
\hline $\begin{array}{l}\text { Tween } 20 \\
\text { POE(20) sorbitan monolaurate }\end{array}$ & 1227.54 & 16.7 & 0.050 & $\begin{array}{l}3.4 \\
5 \\
9 \\
13\end{array}$ & $\begin{array}{l}3.8 \\
3.6 \\
3.5 \\
3.5\end{array}$ & $\begin{array}{l}-7.6 \\
-6.5 \\
-4.0 \\
-3.3\end{array}$ \\
\hline $\begin{array}{l}\text { Tween } 60 \\
\text { POE(20) sorbitan monostearate }\end{array}$ & 1311.70 & 14.9 & 0.021 & $\begin{array}{r}3 \\
5 \\
9 \\
13\end{array}$ & $\begin{array}{l}3.8 \\
3.8 \\
3.7 \\
3.7 \\
\end{array}$ & $\begin{array}{l}-8.5 \\
-8.2 \\
-5.4 \\
-3.9\end{array}$ \\
\hline $\begin{array}{l}\text { Tween } 80 \\
\text { POE }(20) \text { sorbitan monooleate }\end{array}$ & 1309.68 & 15.0 & 0.010 & $\begin{array}{l}3 \\
9\end{array}$ & $\begin{array}{l}5.7 \\
5.5\end{array}$ & $\begin{array}{l}-12.8 \\
-10.1\end{array}$ \\
\hline $\begin{array}{l}\text { Tween } 85 \\
\text { POE }(20) \text { sorbitan trioleate }\end{array}$ & 1838.60 & 11.0 & 0.00029 & $\begin{array}{r}2 \\
3 \\
5 \\
11 \\
13\end{array}$ & $\begin{array}{l}7.9 \\
8.0 \\
7.9 \\
7.8 \\
7.7 \\
\end{array}$ & $\begin{array}{l}-40.7 \\
-48.5 \\
-49.7 \\
-40.1 \\
-34.5\end{array}$ \\
\hline
\end{tabular}


the accurate calculation of $\zeta$ potential requires information about drop size $[6,9]$. The titration was performed manually, for efficiency, even though the device used has an automatic titration option. Solutions of $1 \mathrm{M} \mathrm{HCl}$ and $\mathrm{NaOH}$ were used. Care was taken to read the $\zeta$ potential after $\mathrm{pH}$ was completely stabilized. The time required for this depends largely on the types of dispersed phase and the dispersion medium and it is a very important parameter. In our case, it took several minutes for $\mathrm{pH}$ to reach a steady value.

\section{Results and discussion}

The emulsion obtained had mean drop size around $1.5 \mu \mathrm{m}$ in the absence of electrolyte. The drop size remained constant for at least 3 days after preparation. The type of emulsion (oil-in-water or water-in-oil) was determined using a simple drop dilution test. All emulsions prepared were found to be oil-in-water emulsions. Acoustic and electroacoustic spectrometers present the drop size distribution data in both lognormal and bimodal modes. Note that because the size distribution is on a weight basis, a very small number of large drops can yield a bimodal spectrum. In our case, the percentages of large drops (much larger than mean particle size) are $0.89,0.46$, and $0.42 \%$ at 30,50 , and $70^{\circ} \mathrm{C}$, respectively. To avoid possible exaggeration of the influence of large drops, we chose to work on the lognormal distribution. A similar drop size distribution was obtained for soybean oil emulsions stabilized with a mixture of mono- and diglycerides [10] and palm oil emulsions stabilized by Emulgen 906 [1]. The sunflower emulsions stabilized with SDS presented median sizes decreasing gradually from 0.90 to $0.65 \mu \mathrm{m}$, depending on the emulsifier concentration.

It should be pointed out that manufacturing temperature is an important factor influencing drop size. A 50\%/50\% (w/w) oil-in-water emulsion, stabilized with $10 \%$ (w/w) (on oil) surfactant (Tween 60) was prepared using three different temperatures. Figure 1 reveals that drop size decreases with an increase in temperature.

Figure 2 shows the effects of the type of surfactant and its concentration on the attenuation spectra of the

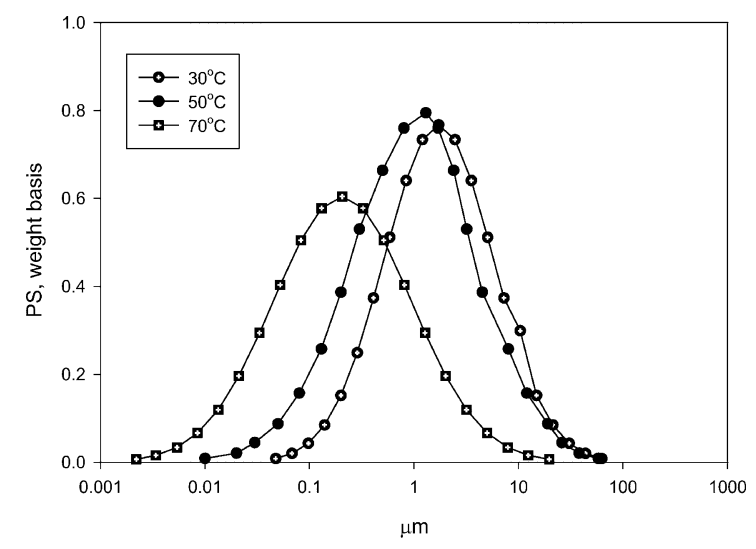

Fig. 1. Drop size distribution at various temperatures. dispersion. The samples without surfactant were found to be unstable, and phase separation occurred when the stirring stopped. According to Table 1, the IEP for naked oil droplets is around 4.5. The addition of surfactant induces a shift in the IEP to a lower level and a more negative $\zeta$ potential. Contamination can have some role in building up the potential. The sonication step after addition of the nonionic surfactant was also reported to lead to an increase in $\zeta$ potential and more stable emulsions [14]. The existence of 20 EO groups capable of creating $\mathrm{H}$ bonds with the $\mathrm{OH}^{-}$cannot be neglected in explaining the more negative charge. The oil droplets stabilized by different nonionic surfactants show different $\zeta$ potentials, but all of them are negatively charged at $\mathrm{pH}$ values higher than 4 . An increase in the concentration of surfactant leads to a decrease in $\zeta$ potential, behavior expected due to the shift of the shear plane. Since the naked oil droplet has a more positive $\zeta$ potential, it is reasonable to assume that the polarization of the interface is caused by EO groups and possibly by a chemical change in the structure of the surfactant during sonication. Addition of surfactant yielded a white milky emulsion. Only Tween 20 was able to stabilize the emulsion at the minimum quantity added ( $3.4 \% \mathrm{w} / \mathrm{w}$ on oil). The other two surfactants employed required a higher concentration to make a relatively stable emulsion (the emulsion does not separate when left at rest). A further increase in surfactant concentration had little effect on the drop size of the sample stabilized by Tween 60 , while it continued to decrease the drop size for the sample stabilized by Tween 85 . Figure 3 reveals that among the surfactants used, Tween 20 yields the smallest drop size, and Tween 80 has the lowest efficiency.

The effect of the weight percentage of oil was studied by fixing the surfactant (Tween 85 )-oil proportion at $10 \%$ $(\mathrm{w} / \mathrm{w})$, and the result is presented in Fig. 4. This figure reveals that the lower the weight percentage of oil, the larger the drops are. It is known that emulsions are thermodynamically unstable and they tend to form cream. Due to the forces between droplets and other kind of hydrodynamic forces the creaming velocity of a concentrated emulsion is low. A critical oil volume fraction was probably reached, and droplets attracted each other, opposing gravitational separation [15].

Often, the usage of oil requires the presence of other additives, in practice. Soybean oil, for instance, usually contains a high concentration of electrolytes. The effects of $\mathrm{pH}$ and electrolyte concentration on the $\zeta$ potential of a 50\%/50\% (w/w) soybean oil emulsion in water, stabilized by Tween $85(10 \% \mathrm{w} / \mathrm{w}$ per oil $)$ is examined, and the results are summarized in Fig. 5. Each $\zeta$ potential value shown in this figure is based on four measurements, and the SD is on the order of $0.165 \mathrm{mV}$. The emulsion free of electrolyte exhibited a low positive $\zeta$ potential at $\mathrm{pH}$ below 3. As can be seen in Fig. 5 the sign of the $\zeta$ potential changes somewhere between $\mathrm{pH}$ 3 and 4 . For one sample, with low electrolyte concentration, the sample was 1:1000 diluted and the variation in $\zeta$ potential as a function of $\mathrm{pH}$ was determined with a light scattering device (Malvern ZetaSizer). The results obtained for $\mathrm{pH}$ 

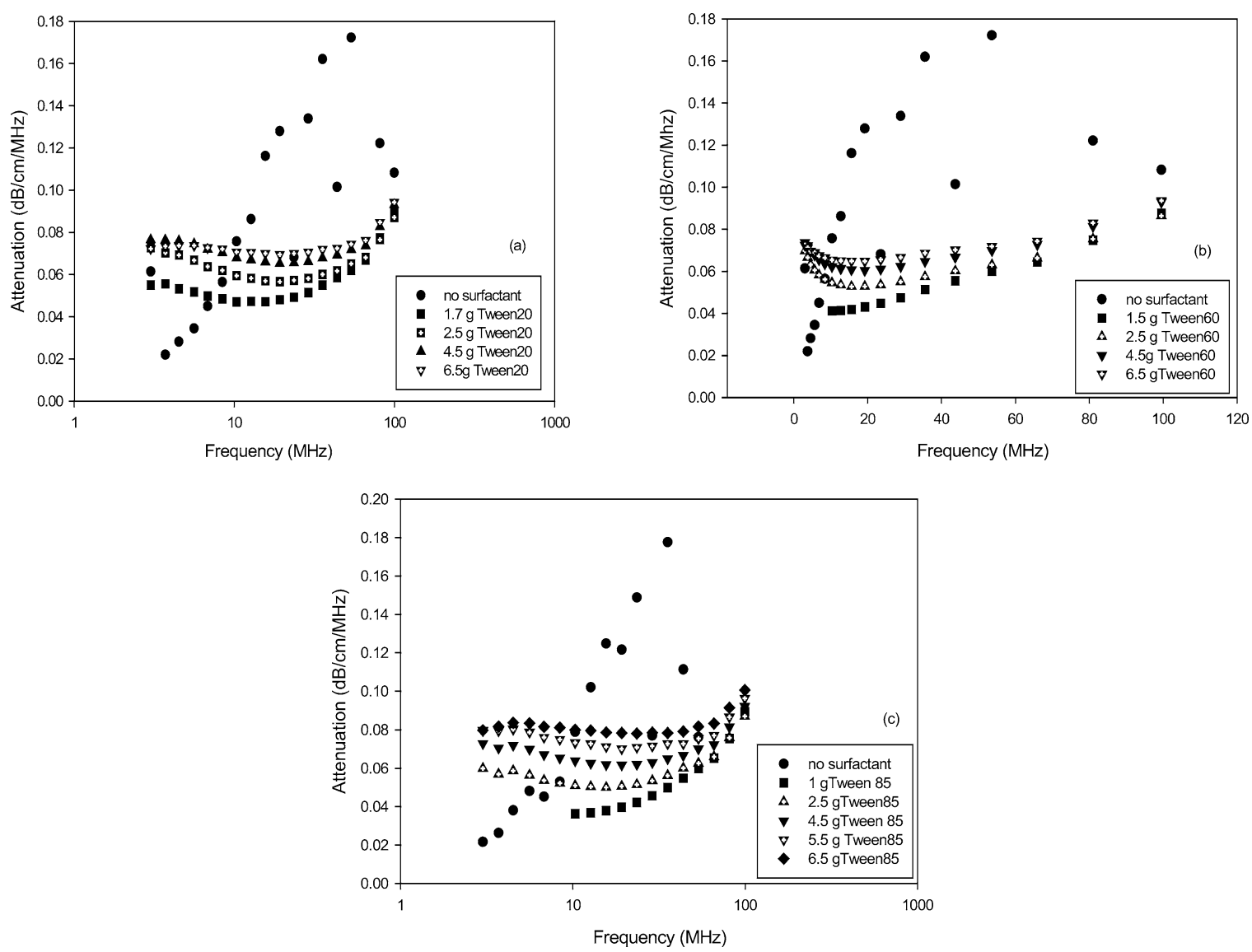

Fig. 2. Attenuation spectrum for various concentrations of surfactant: (a) Tween 20, (b) Tween 60, (c) Tween 85.

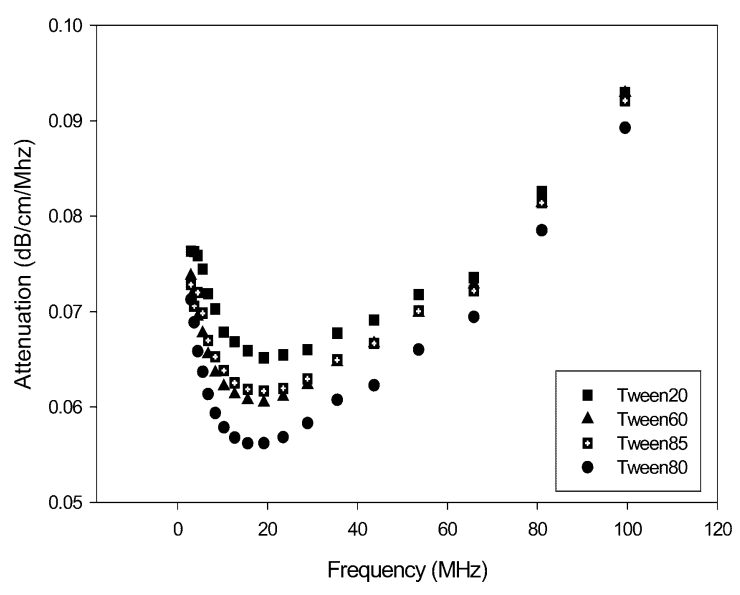

Fig. 3. Attenuation spectrum for various surfactants.

between 2 and 10 are in good agreement with those obtained with the acoustic and electroacoustic devices; for $\mathrm{pH}$ higher than 10 , the acoustic and electroacoustic devices yield lower values. For the case of high ionic strength the light scattering method cannot be applied and such a comparison becomes impossible. Figure 5 shows that in the presence of $0.5 \mathrm{M}$ $\mathrm{NaCl}$, the $\zeta$ potential decreases from $+20 \mathrm{mV}$ at $\mathrm{pH}$ below 3 to $-60 \mathrm{mV}$ at $\mathrm{pH}$ above 10 . Tajima et al. [16] observed the existence of a point of zero charge around $\mathrm{pH} 2.5$ for emul-

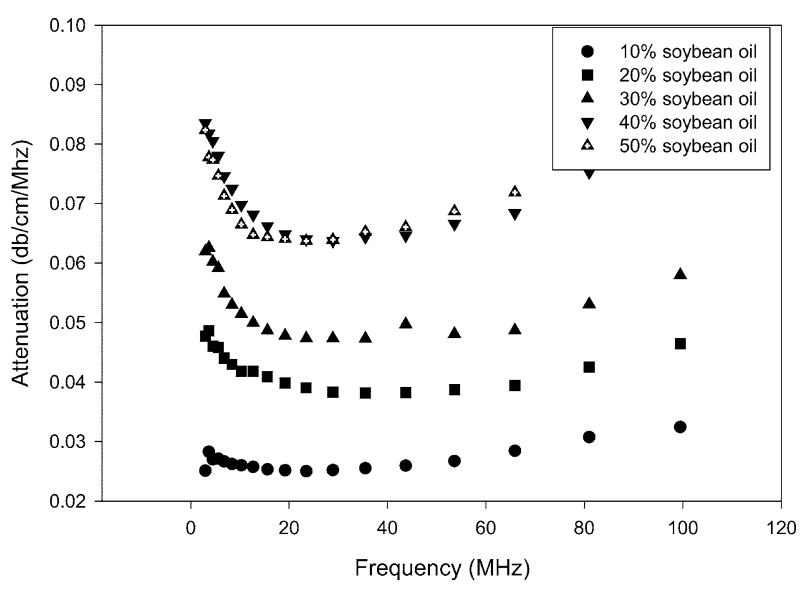

Fig. 4. Attenuation spectra for various oil/water ratios. The surfactant/oil ratio is fixed at $10 \%$.

sions prepared with $\mathrm{C}_{12} \mathrm{H}_{25}(\mathrm{EO})_{3}$ and $\mathrm{C}_{12} \mathrm{H}_{25}(\mathrm{EO})_{6}$, while other articles have reported negatively charged oil drops, the charge being attributed to the hydroxyl ions adsorbed at the oil-water interface $[1,2,17]$. If the concentration of $\mathrm{NaCl}$ exceeds $1 \mathrm{M}$, the emulsion is destabilized and will separate as soon as external stirring is discontinued. Possibly, this is caused by the occurrence of phase inversion, which is reported to be influenced by temperature and is very sensitive to the presence of additives for microemul- 


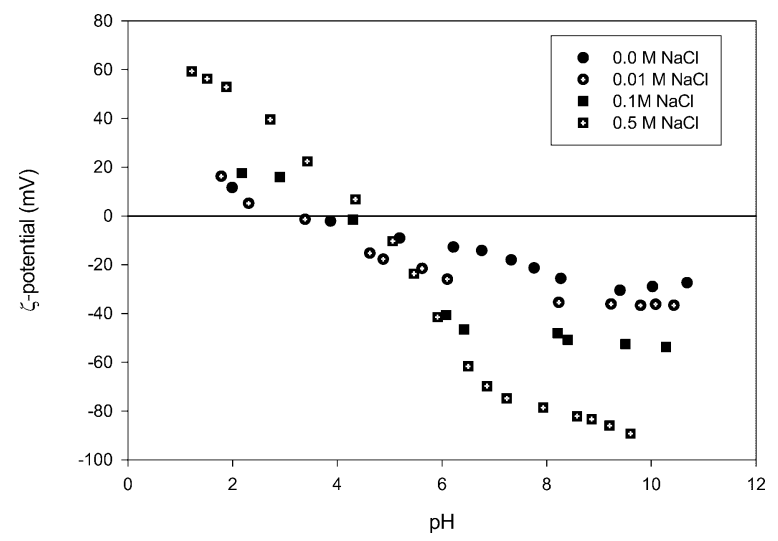

Fig. 5. Variation of $\zeta$ potential as a function of $\mathrm{pH}$ for various concentrations of $\mathrm{NaCl}$.

sions. The $\zeta$ potential in this case drops dramatically from $+60 \mathrm{mV}$ at $\mathrm{pH}$ around 2 to $-80 \mathrm{mV}$ at $\mathrm{pH}$ around 10 . In a study on the mobility of hydrocarbons and their derivatives in oil/water emulsions, Stachurski and Michałek [3] showed that the $\zeta$ potential of drops is highly dependent on $\mathrm{pH}$, especially for alkanes with large numbers of carbon atoms, and the IEP, if it exists, is below pH 3. Also, the negative charge density on the liquid/liquid interface is higher than that on the solid/liquid interface. Carruthers [18] found that the IEP was around 2.7. On the basis of classic diffuse double-layer theory it was concluded that the preferential adsorption of $\mathrm{OH}^{-}$groups is responsible for the negative $\zeta$ potential [3,18]. Marinova et al. [17] proposed that hydrogen bonding exists between $\mathrm{OH}^{-}$ions and water molecules in the boundary layer near the oil/water interface. Though it is generally accepted that the oil/water interface is negatively charged at $\mathrm{pH}$ higher than 3 , the mechanism proposed by Marinova et al. is still questionable [19]. Because the $\zeta$ potential of drops is dependent on $\mathrm{pH}$ even when electrolyte is absent, preferential adsorption or desorption of electrolyte ions, as the most important source of surface charge, can be eliminated. Dunstan and Saville [20,21] and Dunstan [22] reported a difference between the adsorption of certain ions on the oil/water interface and their preferential solubility in the interface region. They suggested that the latter is the possible mechanism, since the actual adsorption is thermodynamically unfavorable. Chibowski and Wiaçek [19] assumed that the water dipoles are immobilized and ordered on the oil interface and the role of $\mathrm{OH}^{-}$and other ions might be structure breaking or making, and they also may be fixed to the dipole layer. An important feature of their result, also observed in Fig. 5, is the decrease in the negative $\zeta$ potential as the concentration of $\mathrm{NaCl}$ increases, behavior that does not follow DLVO theory, which predicts a continuous decrease in $\zeta$ potential with an increase in ionic strength. This behavior has been observed previously, not only for emulsions stabilized by nonionic surfactants, but also for latex particles and naked oil droplets, suggesting a common cause of interface polarization [23].

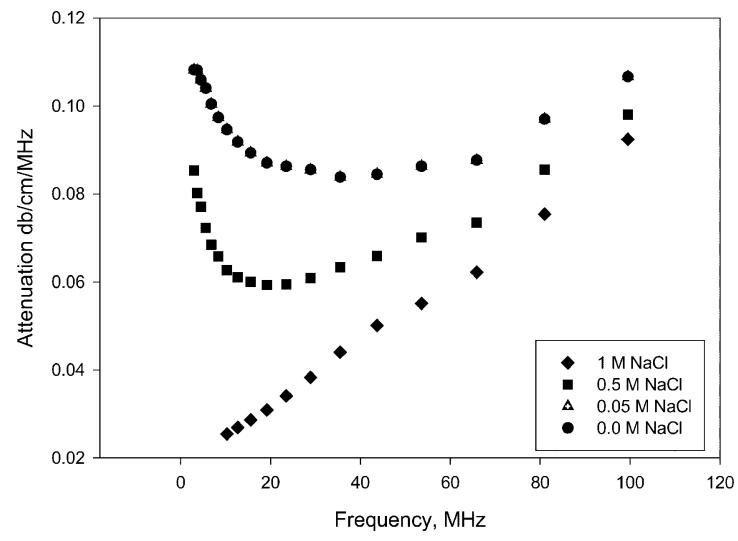

Fig. 6. Attenuation spectrum for various concentrations of $\mathrm{NaCl}$.

The attenuation spectra for various concentrations of $\mathrm{Na}^{+}$ are illustrated in Fig. 6. As can be seen from this figure, the drop size is not influenced by the addition of $\mathrm{NaCl}$ up to a concentration of $0.05 \mathrm{M}$. However, higher salt concentration yields larger drop size until $1 \mathrm{M}$, at which point phase separation occurs. Figure 7 shows the variation in $\zeta$ potential as a function of $\mathrm{pH}$ for various monovalent cations at $1 \mathrm{M}$. This figure reveals that for the largest cation, $\mathrm{K}^{+}$, charge inversion does not occur. In this case, the $\zeta$ potential is almost constant at low $\mathrm{pH}$, decreases between $\mathrm{pH} 3$ and 8 , up to $-80 \mathrm{mV}$, and then slightly levels. The charge reversal point for the case of $\mathrm{Li}^{+}$is a little lower that that for the case of $\mathrm{Na}^{+}$. In general, the absolute $\zeta$ potential of the former is lower than that of the latter. Phase separation was observed for both $\mathrm{Na}^{+}$and $\mathrm{K}^{+}$at the manufacturing temperature of oil $\left(70^{\circ} \mathrm{C}\right)$, but was not observed for $\mathrm{Li}^{+}$. The cloud point seems to be reached at $1 \mathrm{M}$. The surfactants from the Tween series have $20 \mathrm{EO}$ groups, and their dispersion in water is due to the hydrogen bonds between water molecules and these groups. At the cloud point dehydration takes place and the surfactant is separated from the solution along with the oil. When the emulsion was cooled to room temperature and continuously stirred, phase separation persisted in the case of $\mathrm{Na}^{+}$; it was reversible in the case of $\mathrm{K}^{+}$; and it did not appear in the case

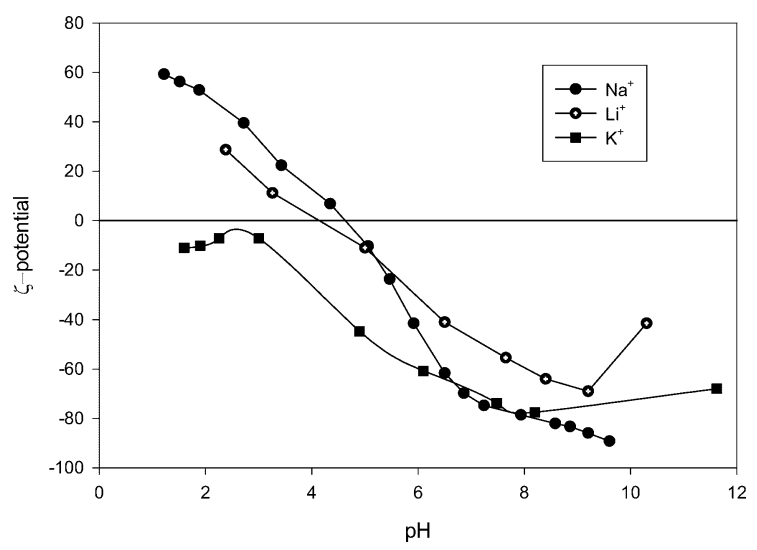

Fig. 7. Variation of $\zeta$ potential as a function of $\mathrm{pH}$ for various monovalent ions. 
of $\mathrm{Li}^{+}$. The same order in the ability of monovalent cations to salt out the oil was reported by Maguro [24]. Since a study of the cloud point is beyond the scope of our study, we simply note that this phenomenon appears to be influenced by additives like $\mathrm{Na}^{+}$and $\mathrm{K}^{+}$in a greater measure than the divalent and trivalent ions used in this study. Warisnoicharoen et al. [12] pointed out that the presence of electrolytes is detrimental to the formation of microemulsions with nonionic surfactant, since it has the effect of reducing the phase inversion temperature (PIT) due to dehydration of the POE group. The influence of oil type and ratio is also reported for microemulsions prepared with nonionic surfactants (Brij 97 and $\mathrm{C}_{12} \mathrm{E}_{10}$ ); high concentrations of triglyceride oils like soybean oil increase the PIT [12]. The inversion from oil-in water to water-in-oil of silicon oil emulsions stabilized with nonionic surfactant is reported at increasing temperature or high concentration of sodium chloride [25].

According to Fig. 8, the variation in $\zeta$ potential as a function of $\mathrm{pH}$ for the case of $\mathrm{CaCl}_{2}$ is similar to that for the case of $\mathrm{MgCl}_{2}$ when the electrolyte concentration is $10^{-3} \mathrm{M}$. If $\mathrm{pH}$ is high, addition of $5 \times 10^{-2} \mathrm{M} \mathrm{NaCl}$ results in a more negative $\zeta$ potential than addition of divalent cations. A similar negative $\zeta$ potential in a short-lived emulsion system containing $\mathrm{NaCl}$ was reported by Stachurski and Michałek [3]. The $\zeta$ potential-versus-pH curves in Fig. 8 intersect around $\mathrm{pH}$ 8.0. Similar behavior was observed by Ho and Ahmad [1], except that charge reversal occurs at low $\mathrm{pH}$ for all three types of cation in our study. It is interesting to note in Figs. 9a and 9b that at high ionic strength the $\zeta$ potential decreases with an increase in $\mathrm{pH}$, reaches a minimum, and then increases again with a further increase in pH. For $0.1 \mathrm{M} \mathrm{CaCl}_{2}$ and $0.5 \mathrm{M} \mathrm{MgCl}_{2}$, a second charge reversal occurs around $\mathrm{pH} 10$. A region of flattened negative charge at high $\mathrm{pH}$ is a common feature of naked oil droplets and is supposedly due to a saturation in hydroxyl ions [18]. Obviously, since droplets attain a positive charge at very high $\mathrm{pH}$, this explanation does not stand anymore. It seems that the appearance of the second charge reversal point depends on the concentration of electrolyte (it appears only at high concentration, as the shear plane shifts

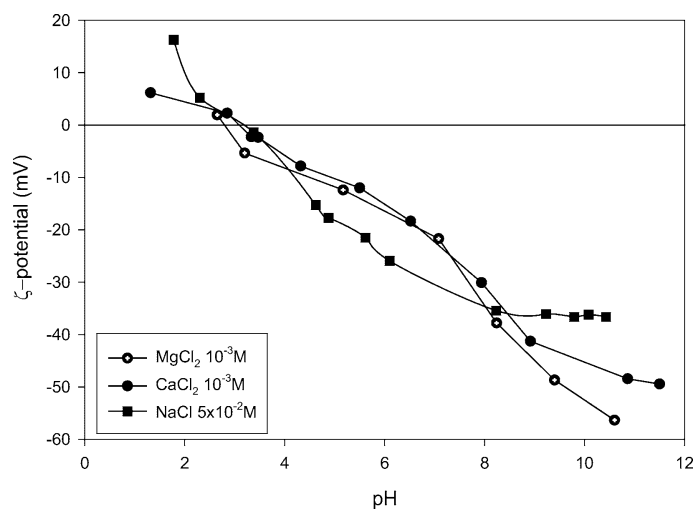

Fig. 8. Variation of $\zeta$ potential as a function of $\mathrm{pH}$ for low concentrations of $\mathrm{Ca}^{2+}, \mathrm{Mg}^{2+}$, and $\mathrm{Na}^{+}$.
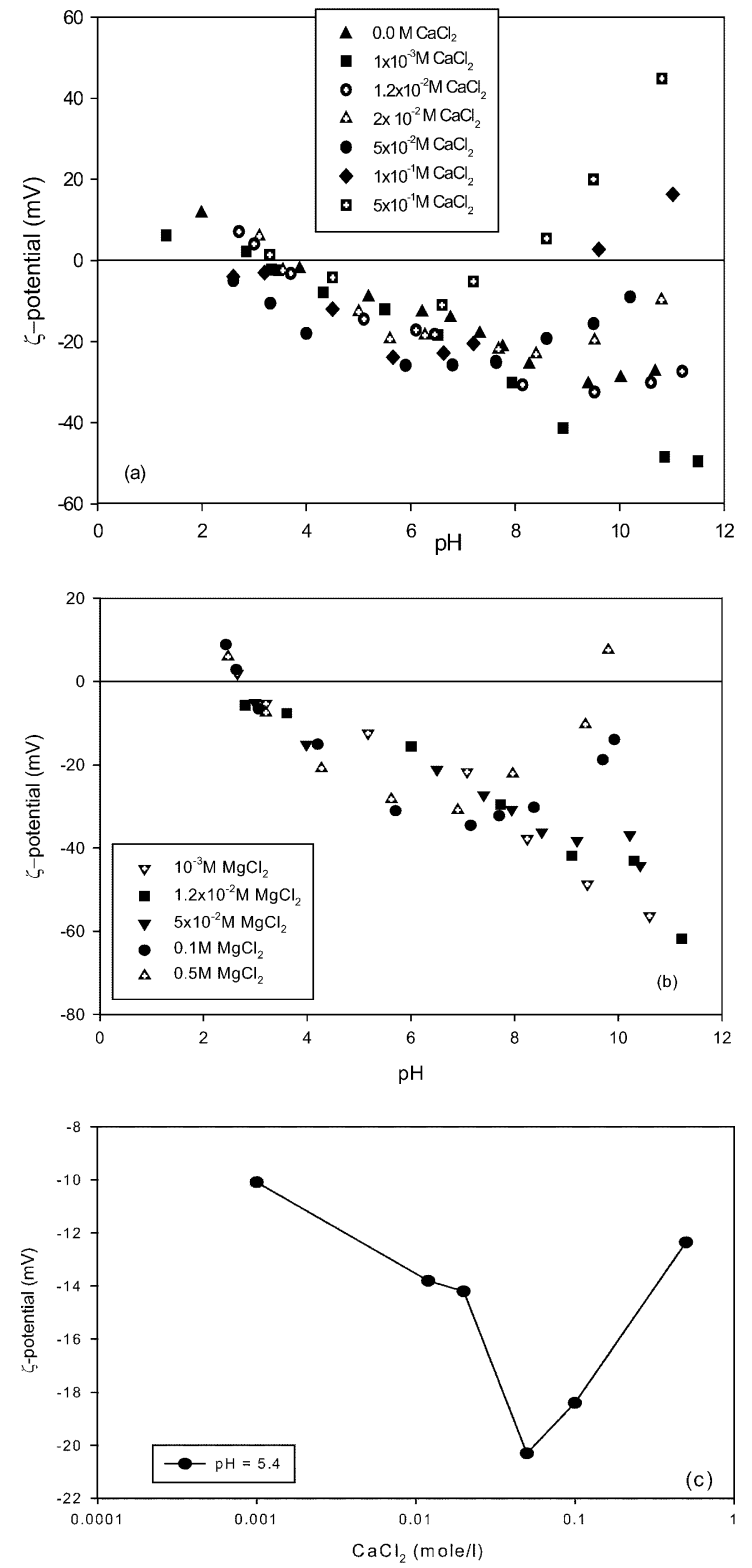

Fig. 9. Variation of $\zeta$ potential as a function of $\mathrm{pH}$ at various concentrations of $\mathrm{CaCl}_{2}$ (a) and $\mathrm{MgCl}_{2}$ (b), and as a function of $\mathrm{CaCl}_{2}$ concentration at pH 5.4 (c).

toward the surfactant/water surface), and it is specific to divalent cations. Figure 9c presents the variation in $\zeta$ potential as a function of $\mathrm{CaCl}_{2}$ concentration. The $\zeta$ potential is found to decrease with an increase in ionic strength, reaches a minimum, and then levels again. As discussed before, this behavior was also observed for naked oil droplets and for oil or latex particles $[1,20,26-29]$. Several possible explanations have been proposed for the origin of this behavior in the case of latex. Elimelech and O'Melia [30] and Miklavic and Ninham [31], for example, suggested a co-ion adsorption mechanism. Zukoski and Saville [32,33] proposed a model for co-adsorption, taking into account the movement of ions within the Stern layer. Another well-known model is the hairy layer [28], which considers the surface to be covered 


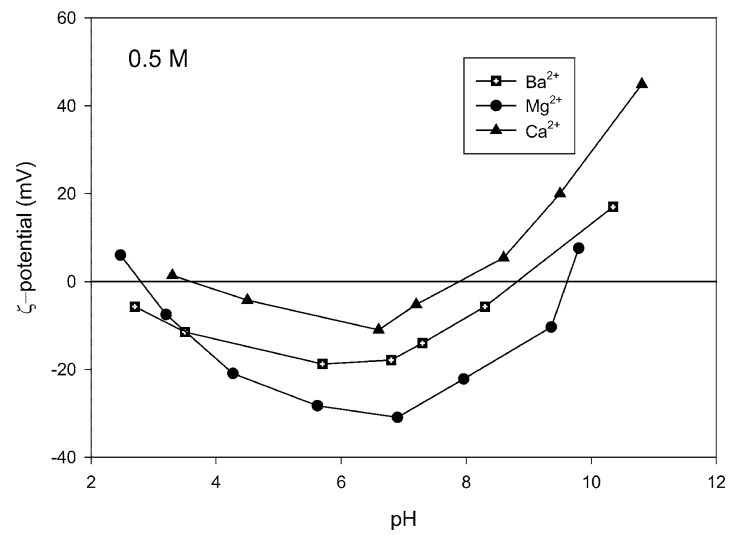

Fig. 10. Variation of $\zeta$ potential as a function of $\mathrm{pH}$ for various divalent ions.

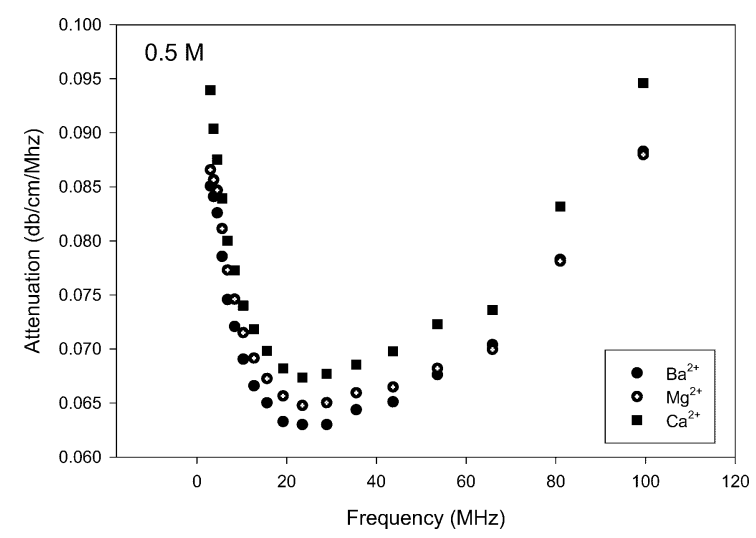

Fig. 11. Attenuation spectrum for various divalent ions.

by a layer of chains carrying the charge; the layer contracts as ionic strength increases, shifting the electrokinetic shear plane. Goetz and El-Aaser [27] studied the effect of electrolyte on the electrokinetic behavior of a toluene-water microemulsion stabilized by cetyl alcohol and SLS. They concluded that the charging mechanism involves either co-ion adsorption or displacement of the nonionic surfactant by the ionic one, or both. Appropriate models for the explanation of the existence of a local minimum of $\zeta$ potential as the concentration of electrolyte varies, however, are not available for the case of emulsions stabilized by nonionic surfactant.

Figure 10 shows the variation in $\zeta$ potential as a function of $\mathrm{pH}$ for three types of divalent cations all at the same concentration of $0.5 \mathrm{M}$. This figure reveals that if $\mathrm{pH}$ is lower than 4, the emulsions for the cases of $\mathrm{Ca}^{2+}$ and $\mathrm{Mg}^{2+}$ exhibit a positive $\zeta$ potential, but that for the case of $\mathrm{Ba}^{2+}$ has a negative $\zeta$ potential even if $\mathrm{pH}$ is as low as 2.5. Charge reversal occurred in all the three cases at high $\mathrm{pH}$ : 7.9 for $\mathrm{Ca}^{2+}, 8.3$ for $\mathrm{Ba}^{2+}$, and 9.5 for $\mathrm{Mg}^{2+}$. The drop size was monitored immediately after preparation of the emulsions, and the corresponding attenuation spectra are presented in Fig. 11. As expected, $\mathrm{Ba}^{2+}$, which is considered to be the most effective flocculating ion, yields the largest drop size. The presence of multiple charge reversal points resembles a
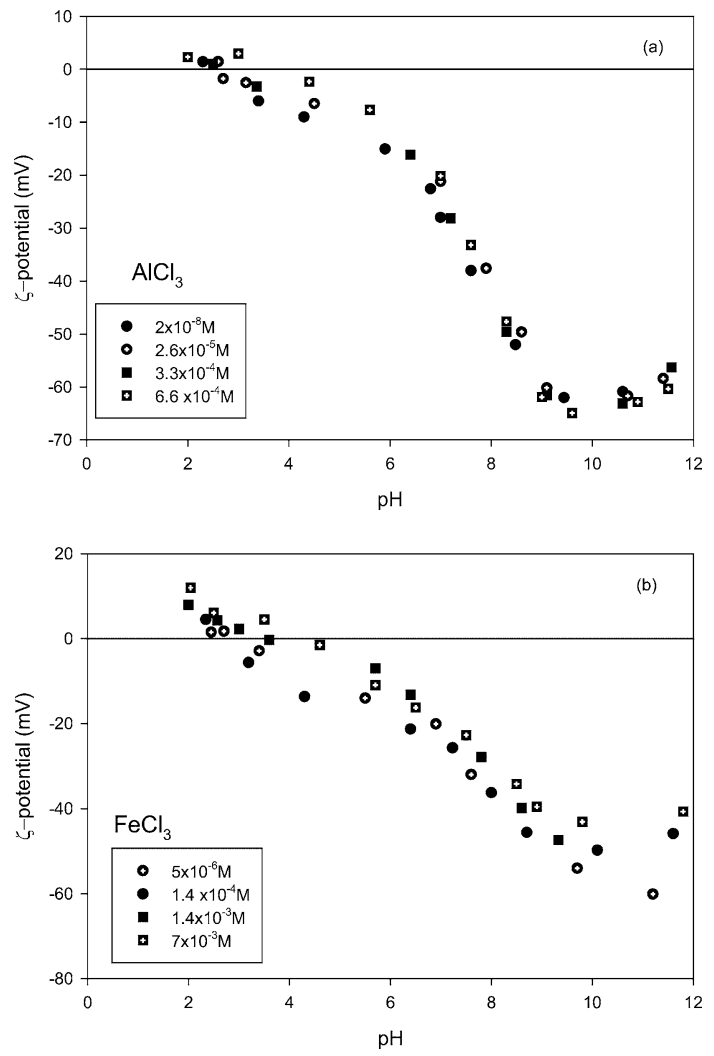

Fig. 12. Variation of $\zeta$ potential as a function of $\mathrm{pH}$ for various concentrations of trivalent cations: (a) $\mathrm{AlCl}_{3}$, (b) $\mathrm{FeCl}_{3}$.

dispersion in which hydrolyzable cationic species like $\mathrm{Zn}^{2+}$ and $\mathrm{Cu}^{2+}$ are used [1].

The variation in $\zeta$ potential as a function of $\mathrm{pH}$ for various concentrations of trivalent ions is shown in Fig. 12. As can be seen from this figure, the variation in $\zeta$ potential for the case of $\mathrm{Al}^{3+}$ is similar to that for the case of $\mathrm{Fe}^{3+}$. That is, the $\zeta$ potential is positive at low $\mathrm{pH}$, undergoes a charge reversal and becomes more negative as $\mathrm{pH}$ is increased, and has a local minimum near $\mathrm{pH} 10$. The point of zero charge shifted to higher $\mathrm{pH}$ as the electrolyte concentration increased. The extent of the shift is less significant than that reported by Ho and Ahmad [1] and the shape of our curve is less concave downward than theirs. The concave downward tendency of a $\zeta$ potential-versus-pH curve and its significant positive branch were explained by Ho and Ahmad as due to the adsorption of hydrolyzed species, which are expected to form in the case of high concentrations of trivalent cations, to the emulsion surface. In their study positive $\zeta$ potentials were observed at $\mathrm{pH}$ lower than 9 for $8 \times 10^{-4}$ $\mathrm{M} \mathrm{Fe}^{3+}$, and at $\mathrm{pH}$ lower than 10 for $5 \times 10^{-5} \mathrm{M} \mathrm{Al}^{3+}$. Figure 12 reveals that the addition of $\mathrm{Fe}^{3+}$ has the effect of decreasing the negative $\zeta$ potential up to $-60.1 \mathrm{mV}$, while the addition of $\mathrm{Al}^{3+}$ has the effect of decreasing the negative $\zeta$ potential up to $-67 \mathrm{mV}$, and decreasing the positive $\zeta$ potential from $+12 \mathrm{mV}$ for the case of an electrolyte-free emulsion to $+2 \mathrm{mV}$. At the concentrations examined in the present study, however, $\mathrm{Al}(\mathrm{OH})_{3}$ and $\mathrm{Fe}(\mathrm{OH})_{3}$ are the domi- 
nant species, as can be inferred from the solubility diagrams for the two hydroxides [34]. At $10^{-4} \mathrm{M}, \mathrm{Al}^{3+}$ precipitates almost completely at $\mathrm{pH}$ higher than 4 , and the same occurs to $\mathrm{Fe}^{3+}$ at $10^{-6} \mathrm{M}$. The white aluminum hydroxide precipitate was invisible since the emulsion is the same color, but ferric hydroxide precipitate could be seen clearly to deposit on the bottom of the beaker at concentrations as high as $10^{-4} \mathrm{M}$. It seems that for the trivalent cations examined, the effect of hydrolyzed species is more significant when the electrolyte concentration is high than when it is low. Since the $\zeta$ potential-versus-pH curves for various concentrations of electrolytes do not show significant differences, the adsorption of hydrolyzed species onto the surface of emulsion drops, as reported by Ho and Ahmad [1], does not occur in our case.

\section{Acknowledgment}

This work is supported by the National Science Council of the Republic of China.

\section{References}

[1] C.C. Ho, K. Ahmad, J. Colloid Interface Sci. 216 (1999) 25.

[2] K. Ahmad, C.C. Ho, W.K. Fong, D. Toji, J. Colloid Interface Sci. 181 (1996) 595.

[3] J. Stachurski, M. Michałek, J. Colloid Interface Sci. 184 (1996) 433.

[4] N. Pilpel, M.E. Ribbani, J. Colloid Interface Sci. 119 (1987) 550.

[5] S. Fukushima, Surf. Sci. Ser. 15 (1984) 369.

[6] T.H. Wines, A.S. Dukhin, P. Somasundaran, J. Colloid Interface Sci. 216 (1999) 303.

[7] L. Kong, J.K. Beattie, J.R. Hunter, J. Colloid Interface Sci. 238 (2001) 70.

[8] L. Kong, J.K. Beattie, J.R. Hunter, Colloid Polym. Sci. 279 (2001) 678.
[9] S. Takeda, N. Tobori, H. Sugawara, K. Furusawa, Electrical Phenom. Interfaces 76 (1998) 273.

[10] M. Kako, S. Kondo, J. Colloid Interface Sci. 69 (1979) 163.

[11] M. Miñana-Perez, A. Graciaa, J. Lachaise, J.L. Salanger, Colloids Surf. A 100 (1995) 217.

[12] W. Warisnoicharoen, A.B. Lansley, M.J. Lawrence, Int. J. Pharm. 198 (2000) 7.

[13] S.K. Hait, S.P. Moulik, J. Surf. Deterg. 4 (2001) 303.

[14] G. Stalidis, A. Avranas, D. Jannakoudakis, J. Colloid Interface Sci. 135 (1990) 313.

[15] D.J. McClements, Food Emulsions: Principles, Practice, and Techniques, CRC Press, New York, 1999.

[16] K. Tajima, M. Koshinuma, A. Nakamura, Colloid Polym. Sci. 270 (1992) 759

[17] K. Marinova, R. Alargova, G. Denkov, N.D. Velev, O.D. Petsev, D.N. Ivanov, I.B. Borwankar, Langmuir 12 (1996) 2045.

[18] J. Carruthers, Trans. Faraday Soc. 34 (1938) 300.

[19] E. Chibowski, A. Wiaçek, Surf. Sci. Ser. 106 (2002) 893.

[20] D.E. Dunstan, D.A. Saville, J. Chem. Soc. Faraday Trans. 88 (1992) 2031.

[21] D.E. Dunstan, D.A. Saville, J. Chem. Soc. Faraday Trans. 89 (1993) 527.

[22] D.E. Dunstan, J. Phys. Chem. 97 (1993) 11143.

[23] K. Yoshihara, H. Ohshima, N. Momozawa, H. Sakai, M. Abe, Langmuir 11 (1995) 2979.

[24] M.R. Porter, Handbook of Surfactants, Blackie Academic \& Professional, Glasgow, 1994.

[25] B.P. Binks, J. Dong, Colloids Surf. A 132 (1998) 289.

[26] O. Boen Ho, Surf. Sci. Ser. 106 (2002) 869.

[27] R. Goetz, M.S. El-Aaser, J. Colloid Interface Sci. 142 (1991) 317.

[28] M.S. Ramero-Cano, A. Martín-Rodríguez, G. Chauveteau, F.J. de las Nieves, J. Colloid Interface Sci. 198 (1998) 273.

[29] A.J. Taylor, F.W. Wood, Trans. Faraday Soc. 53 (1957) 523.

[30] M. Elimelech, C.R. O'Melia, Colloids Surf. 44 (1990) 165.

[31] S.J. Miklavic, B.W. Ninham, J. Colloid Interface Sci. 134 (1990) 325.

[32] C.F. Zukoski, D.A. Saville, J. Colloid Interface Sci. 114 (1986) 32.

[33] C.F. Zukoski, D.A. Saville, J. Colloid Interface Sci. 114 (1986) 45.

[34] W. Stumm, J.J. Morgan, Aquatic Chemistry, Wiley-Interscience, New York, 1996. 